\title{
Thermodynamic Analysis of Kapitza Cycle based on Nitrogen Liquefaction
}

\author{
Vijay Singh Bisht \\ Assistant Professor Department of Mechanical Engineering, Uttaranchal University, \\ Dehradun, Uttarakhand, India
}

\begin{abstract}
Cryogenic technology is used for liquefaction of many gases and it has several applications in food process engineering. The thermodynamic analysis of various cryogenic systems for liquefaction of different gases has been done by many researchers. Thermodynamic analysis of a nitrogen liquefaction system based on Kapitza cycle which is a modified Claude cycle has been carried out to evaluate various vital parameters of the system.

Parametric evaluation using EES Commercial helps to identify the effects of expander flow fraction, isentropic efficiency of expander on the FOM (figure of merit) of the liquefaction cycle.

The study computes helps in selecting expander flow fraction, operating temperature levels of expanders, and approach temperature of the heat exchangers through them. Results from the analysis may help evolving guidelines for designing appropriate thermodynamic cycles for practical nitrogen liquefaction systems.
\end{abstract}

\section{INTRODUCTION}

The word cryogenics stems from Greek and means "the production of freezing cold". The science and technology of producing a low-temperature environment is generally referred to as cryogenics. It is perhaps appropriate to start with some definitions. The word cryogenics has its origin in the Greek language where "cryos" means frost or cold and "gen" is a common root for the English verb to generate. However, the term is used today as a synonym for the low-temperature state. It is not well-defined at what point on the temperature scale refrigeration ends and cryogenics begins, but most scientists assume it starts at or below $-150{ }^{\circ} \mathrm{C}$ or $123 \mathrm{~K}$ (about $-240{ }^{\circ} \mathrm{F}$ ). The National Institute of Standards and Technology at Boulder, Colorado has chosen to consider the field of cryogenics as that involving temperatures below $-180{ }^{\circ} \mathrm{C}\left(-292{ }^{\circ} \mathrm{F}\right.$ or $\left.93.15 \mathrm{~K}\right)$. This is a logical dividing line, since the normal boiling points of the so-called permanent gases (such as helium, hydrogen, neon, nitrogen, oxygen, and normal air) lie below $-180{ }^{\circ} \mathrm{C}$ while the Freon refrigerants, hydrogen sulfide, and other common refrigerants have boiling points above $-180^{\circ} \mathrm{C}$.

The cryogenic mean literally, the production of ice cold, however the term is used today as a for low temperatures. Cryogenics is defined as that branch of physics which deals with the production of very low temperatures and their effect on matter a formulation which addresses both aspects of attaining low temperatures which do not naturally occur on Earth, and of using them for the study of nature or the human industry. In a more operational way it is also defined as the science and technology of temperatures below $123 \mathrm{~K}$.

1). $0.01-.1 \mathrm{k}=$ Dilution refrigerator

2). $1-10 \mathrm{k}=$ Magnetic refrigerator

3). $10-50 \mathrm{k}=$ Liquid helium

4). $50-123 \mathrm{k}=$ Air liquefies

\section{APPLICATION OF LIQUID NITROGEN IN FOOD PROCESSING [4][5][7][8][9]}

1.Freezing of baked goods, shrimp, meats, soups, and so on requires a process known as CRYO-QUICK in the food processing industry.

2.Liquid nitrogen is widely used in food processing and food transportation because of minimum production costs.

3. Cryogenic (i.e., very low-temperature) freezing results in smaller weight losses from dehydration than traditional mechanical freezing. Frozen food processors can thus preserve the quality of. Their products with a freezing system that uses environmentally friendly liquid nitrogen.

4. Due to its own extremely cold temperature, liquid nitrogen can enable a cryogenic system to freeze food within minutes instead of the hours traditionally required with other systems The faster freezing causes the formation of small ice crystals, which then help ensure product moisture and quality are maintained longer.

5.In freezing on microbial flora of ground beef patties. It was observed that $\mathrm{LN}_{2}$ freezing produced significantly greater reduction in microbial activity than the mechanical air blast freezer. Patties containing $30 \%$ fat provided greater. 
6. $\mathrm{LN}_{2}$ freezing of prawns over. It was reported that the beneficial effect of $\mathrm{LN} 2$ freezing over conventional plate freezing can exist even after 59 days at a commercial storage temperature of $255 \mathrm{~K}$.

7.The use of $\mathrm{LN}_{2}$ as a secondary refrigerant along with ice for transportation of wet fish. It is found that the ice melting rate can be reduced by about $50 \%$.

8. The freezing point and freezing rate of tilapia meat in LN2 freezers at 186 and $145 \mathrm{~K}$. It is found that the freezing rate in $\mathrm{LN}_{2}$ freezing is independent of thickness of the product to be frozen.

9. Liquid nitrogen used in polar stream system for refrigerated transportation of frozen fish.

\title{
II. KAPITZA LIQUEFACTION SYSTEM[2]
}

Kapitza (1939) modified the basic Claude system by eliminating the third heat exchanger or low temperature heat exchanger. Several notable practical modifications were also introduced in this system a rotary expansion engine was instead of reciprocating expander. The first or high temperature heat exchanger in the kapitza system was actually a set of valved regenerators, which combined the cooling process with the purification process. The incoming warm gas was cooled in one unit and impurities were deposited there, while the outgoing stream warmed up in the other unit and flushed out the frozen impurities deposited in it. Kapitza did a careful analysis of turbo-refrigeration and developed radial flow turbines for air refrigeration.

\subsection{Components Used[2]}

1. COMPRESSOR: - It is a device used to reduce the volume of gaseous air and increase the pressure. Generally for cryogenic application compressor with high compression ratio are used. To achieve high stage compression ratio a number of compressor are used in series rather using a single compressor. It also reduces work consumption. For present work isothermal compression process is used.

2. Expander: - A rotary expansion engine was used have high efficiency than reciprocating engine and the loss also less in rotary expender.

3. HEAT EXCHANGER: - Heat exchangers are devices which transfer heat from hot fluid stream to cold fluid stream. In heat exchanger hot fluid temperature decreases and there is increase in temperature of cold fluid. By losing heat hot fluid is prepared for throttling process and similarly by gaining heat cold fluid heated up for compression process.

4. VALVE: - A throttling valve is used to reduce the pressure of the compressed air so that liquid air can be produced and stored. The process is assumed to be isenthalpic expansion.

5.SEPARATOR/DISTILLATION COLUMN: - In this chamber air is separated into desired components like liquid $\mathrm{N}_{2}$, liquid $\mathrm{O}_{2}$ etc. and the gaseous part is again recirculated.

6. MIXER: - It is a device helps to maintain a constant flow rate of air into the compressor. The extra amount of air is added into incoming stream from separator. The process is assumed to be isobaric.

\subsection{Advantages [3]}

1. A rotary expansion engine of high isentropic efficiency is used instead of reciprocating engine as in Claude cycle.

2.First heat exchanger replaced by a set of valved regenerators which combined the cooling process with purification process.

3.Kapitza cycle can be operate at relatively low pressure is lower than critical pressure of nitogen gas.

\section{MATHEMATICAL MODEL}

A computer program has been developed depending upon the requirements of engineering equation solver (EES). The equations are written in the equation window of EES in the FORTRAN LANGUAGE. EES solves these equations itself on giving 'calculate' command [10].

\author{
Assumptions: \\ 1. The system is at steady state condition. All processes are steady flow processes. \\ 2. Neglecting the effects of kinetic and potential energy in analysis of all the components of system \\ 3.There is no heat in-leak to the system. \\ Mass balance \\ Let $\dot{\mathrm{m}}=$ mass flow rate of $\mathrm{N}_{2}$ compressed $=0.1 \mathrm{~kg} / \mathrm{s}$ \\ $\dot{\mathrm{m}}_{\mathrm{e}}=$ mass flow rate of $\mathrm{N}_{2}$ bypassed to the expander $=0.06 \dot{\mathrm{m}} \mathrm{kg} / \mathrm{s}$ \\ $\dot{\mathrm{m}}_{4}=$ mass flow rate of $\mathrm{N}_{2}$ passing through the second heat exchanger $=0.04 \dot{\mathrm{m}} \mathrm{kg} / \mathrm{s}$
}


$\dot{\mathrm{m}}=\dot{\mathrm{m}}_{\mathrm{e}}+\dot{\mathrm{m}}_{4}$

$\mathrm{x}_{\mathrm{e}}=\frac{\dot{\mathrm{m}}_{\mathrm{e}}}{\dot{\mathrm{m}}}=$ fraction of nitrogen gas going to expander

$\dot{\mathrm{m}}_{6}=$ mass flow rate of liquid $\mathrm{N}_{2}$ produced

$\mathrm{y}=\frac{\mathrm{m}_{6}}{\dot{\mathrm{m}}}=$ liquid yield

Applying First Law for steady flow to the heat exchangers, the expansion valve and the liquid receiver as a unit excluding compressor, for no external heat transfer to the control volume then

$\left(\dot{\mathrm{m}}-\dot{\mathrm{m}}_{6}\right) \mathrm{h}_{10}+\dot{\mathrm{m}}_{6} \mathrm{~h}_{6}+\dot{\mathrm{m}}_{11} \mathrm{~h}_{11}-\dot{\mathrm{m}}_{2}-\dot{\mathrm{m}}_{\mathrm{e}} \mathrm{h}_{3}=0$

On arranging terms and putting value of $\mathrm{x}_{\mathrm{e}}$ and $\mathrm{y}$ we get

$\mathrm{y}=\frac{\dot{\mathrm{m}}_{6}}{\dot{\mathrm{m}}}=\frac{\mathrm{h}_{10}-\mathrm{h}_{2}}{\mathrm{~h}_{10}-\mathrm{h}_{6}}-\mathrm{x}_{\mathrm{e}} \times \frac{\mathrm{h}_{3}-\mathrm{h}_{11}}{\mathrm{~h}_{10}-\mathrm{h}_{6}}$

In case of actual system we consider isentropic efficiency of turbine

$\eta_{\mathbf{e}}=\frac{\mathbf{h}_{3}-\mathbf{h}_{11}}{\mathbf{h}_{3}-\mathbf{h}_{11}}$

Then yield becomes

$$
\mathrm{y}=\frac{\mathrm{m}_{6}}{\dot{\mathrm{m}}}=\frac{\mathrm{h}_{10}-\mathrm{h}_{2}}{\mathrm{~h}_{10}-\mathrm{h}_{6}}-\mathrm{x}_{\mathrm{e}} \times \frac{\mathrm{h}_{3}-\mathrm{h}_{11}}{\mathrm{~h}_{10}-\mathrm{h}_{6}}
$$

Theoretical minimum work requirement or the system [1]

$\dot{\mathrm{w}}_{\mathrm{i}}=\mathrm{T}_{1}\left(\mathrm{~s}_{1}-\mathrm{s}_{6}\right)-\left(\mathrm{h}_{1}-\mathrm{h}_{6}\right)$

work requirement for the system

$\dot{\mathbf{w}}=\left(\frac{1}{\mathbf{y}}\right)\left[\left\langle\mathbf{T}_{1}\left(\mathbf{s}_{1}-\mathbf{s}_{2}\right)-\left(\mathbf{h}_{1}-\mathbf{h}_{2}\right)\right\rangle-\mathbf{x}_{\mathbf{e}}\left(\mathbf{h}_{3}-\mathbf{h}_{11}\right)\right]$

Considering isentropic efficiency of turbine, the actual work requirement

$\dot{\mathrm{w}}=\left(\frac{1}{\mathrm{y}}\right)\left[\left\langle\mathrm{T}_{1}\left(\mathrm{~s}_{1}-\mathrm{s}_{2}\right)-\left(\mathrm{h}_{1}-\mathrm{h}_{2}\right)\right\rangle-\eta_{\mathrm{e}} \mathrm{x}_{\mathrm{e}}\left(\mathrm{h}_{3}-\mathrm{h}_{11}\right)\right]$

\subsection{Figure of merit (FOM) [1]}

It is defined as the ratio of theoretical work requirement and actual work requirement for the system.

The figure of merit is a number between 0 and 1.It gives measure of how closely the actual system approaches the ideal system performance. If the figure of merit greater than unity, it would be in violation of the second law of thermodynamics. The above equation is of FOM is for liquefaction system.

$$
\mathbf{F O M}=\frac{\dot{\mathbf{W}}_{\mathbf{I}}}{\dot{\mathbf{W}}}
$$

\section{Kapitza system}

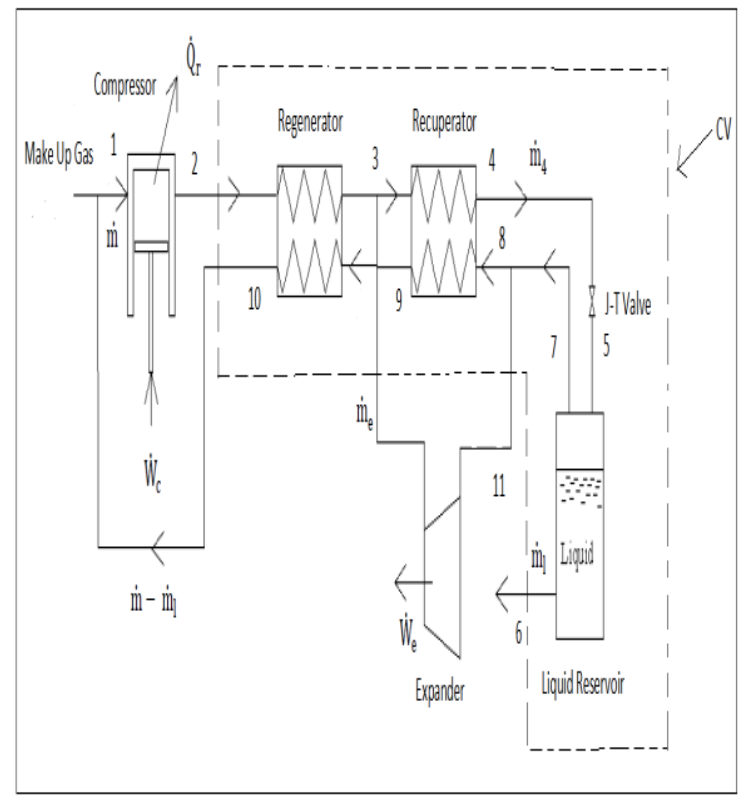

Fig. 1 Kapitza system 


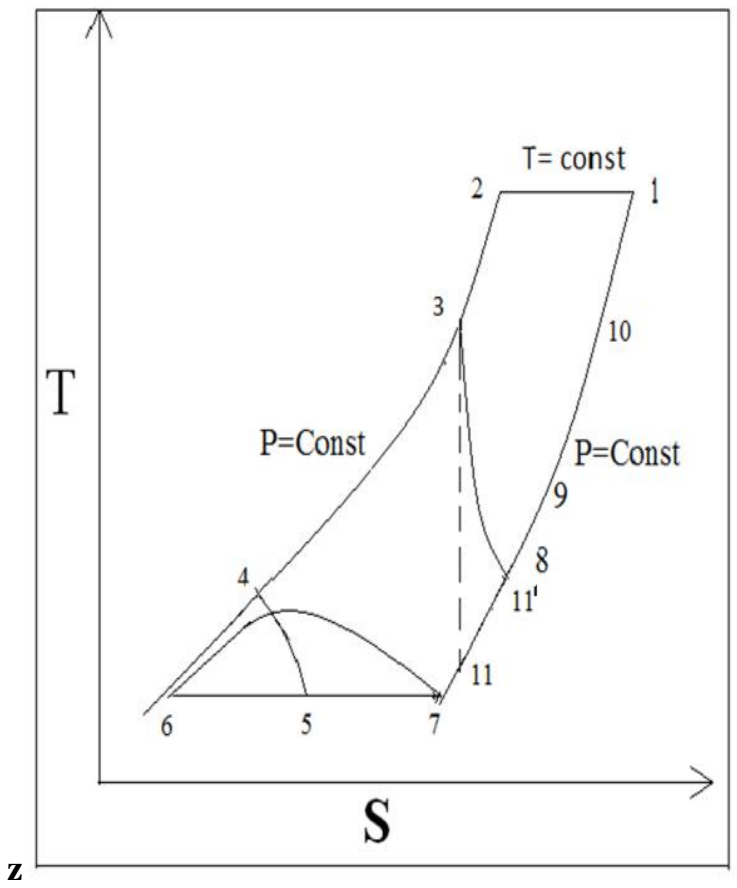

Fig.2 Kapitza cycle on T-s plane

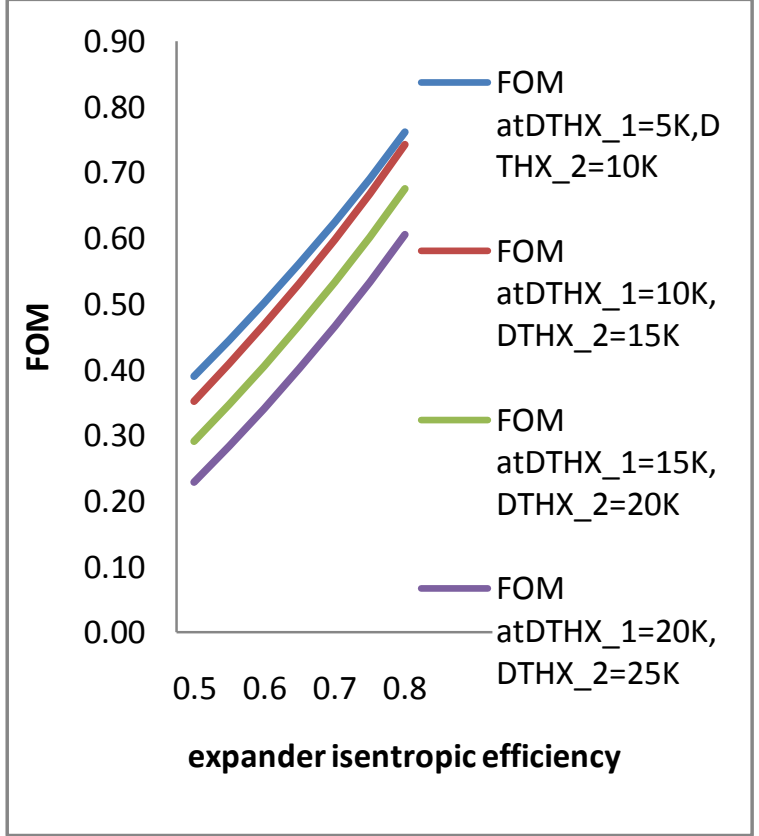

Fig.3 Plot Variation of for with efficiency of expander and FOM 


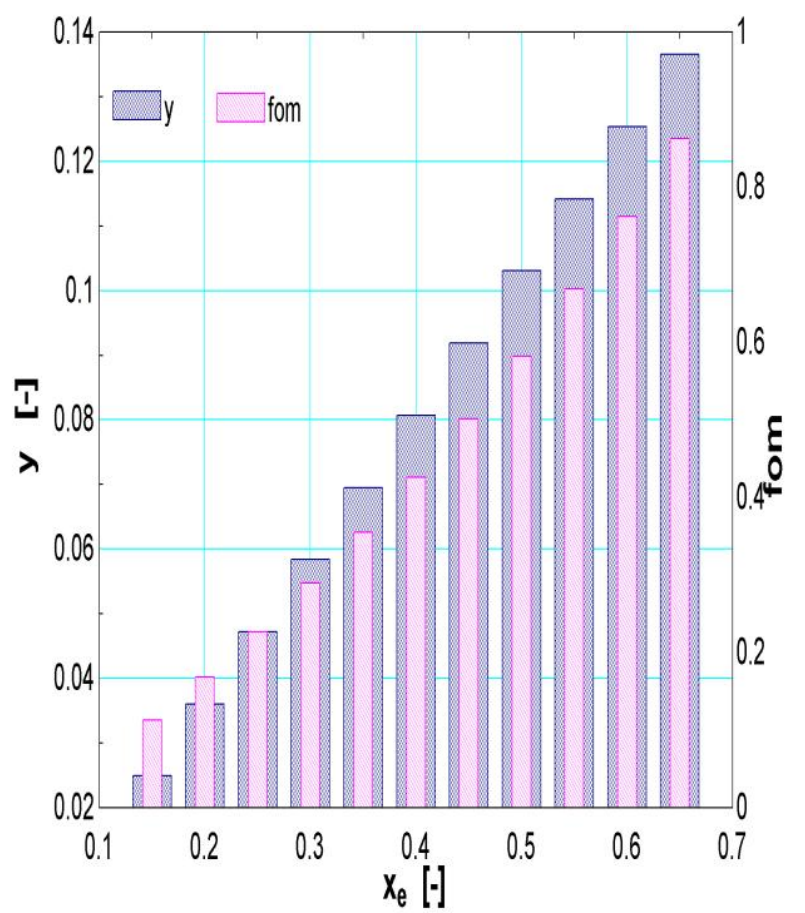

Fig. 4 Plot of Yield and FOM with different fraction of nitrogen going to expander.

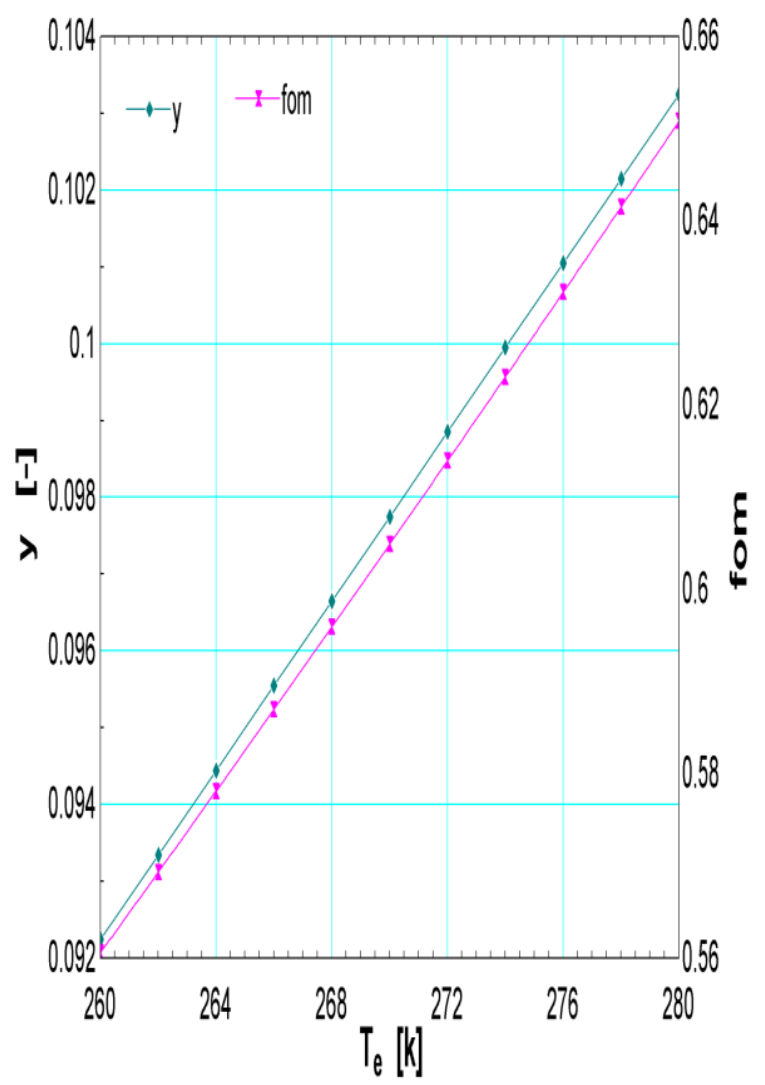

Fig. 5 Plot of Yield and FOM at different expander tempretures. 


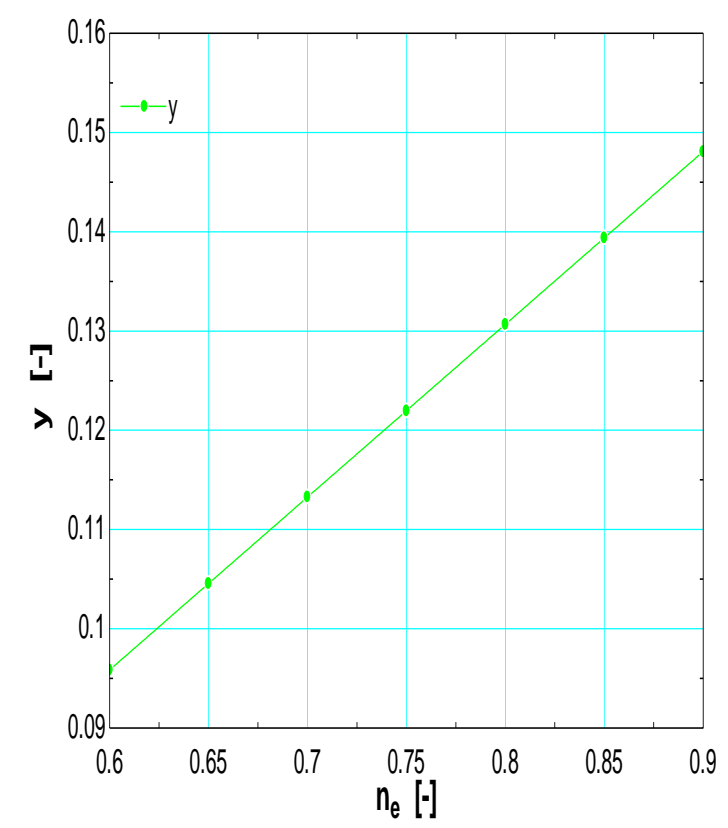

Fig. 6 Plot of Yield against expander efficiency.

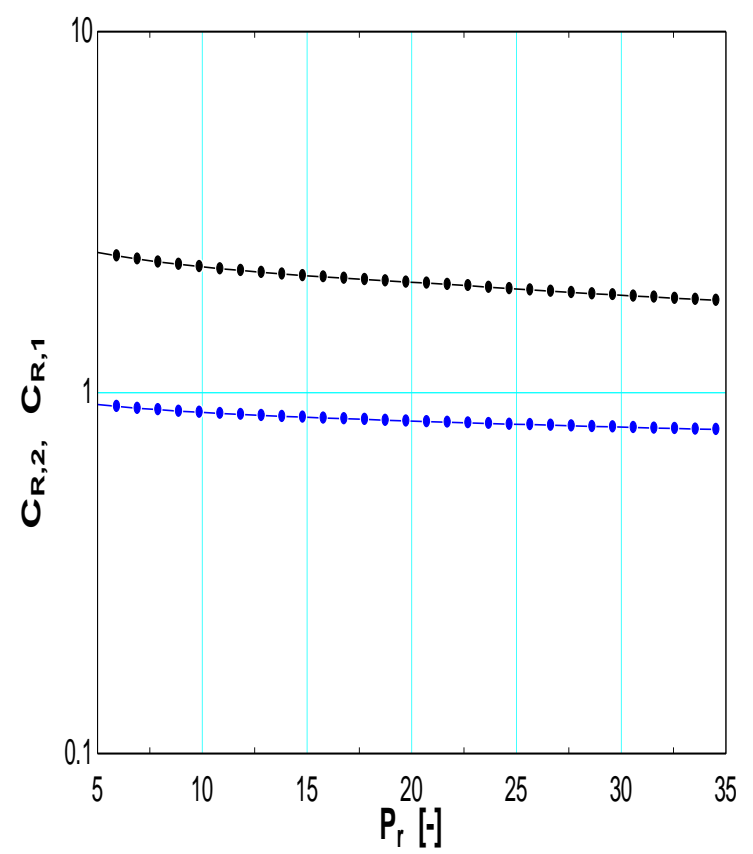

Fig. 7 Plot of pressure ratio at different heat capacity ratio of heat exchangers.

\section{RESULTS AND DISCUSSION}

A mathematical model has been developed for theestimation of yield of liquid nitrogen produced and FOM (figure of merit) of Kapitza system for varying compressor exit pressure,expander flow rate ratio, and isentropic efficiency of expander, approach temperature of regenerator and heat exchanger and inlet temperature of expander

1. From figure 3 the plot between expander efficiency and FOM at different approach temperatures of regenerator and heat exchanger, we conclude at given expander efficiency that the best FOM is achieved at 5 $\mathrm{K}$ and $10 \mathrm{~K}$ approach temperature of regenerator and heat exchanger respectively.As shown in graph by considering various approach tempratures for regenerator and heat exchanger the curve of $5 \mathrm{~K}$ and $10 \mathrm{~K}$ approach temperature of regenerator and heat exchanger have highest value of FOM obtained is approximately .78 . 
2 From fig. 4 Plot of Yield and FOM with different fraction of nitrogen going to expander, shows that both yield and FOM increases. It appears that to maximize the y(yield) $\mathrm{x}$ (expander flow rate ratio) should take on its maximum value, however conservation of mass flow requires that $y+x \leq 1$, because some gas also returned from lower pressure side for cooling of heat exchangers.

3. plot between expander inlet temperature as input parameter or independent parameter,yield and FOM are dependent parameters both yield and FOM increases with increase in expander inlet temperature. The liquid yield rise is more sensitive than the fom,we here take care the range of expander inlet temperature from 260 to $280 \mathrm{k}$ because we also have taken care of cooling done by regenerator at given approach temperature.

4. As from figure 6 to study the impact of expander efficiency on the performance of Kapitza liquefaction cycle, isentropic efficiency of the expanders is varied in a practically possible range $55-85 \%$. When varying the isentropic efficiency of expander observed from the Fig. 6 that the relationships between the liquid production and the isentropic efficiency of expanders are almost linear and the trends are very similar to each other.

5.It is been found that for $\mathrm{HX} 1$ Heat Capacity Ratio $\mathrm{CR}_{1}$ is less than 1 which is resulting from the reduced return stream flow due to withdrawal of liquid from the cycle. For HX2 that are connected in parallel to the expander, the return stream flow is higher, and therefore, they always have CR greater than 1 . This is due to the reason that a part of the high pressure stream (forward stream) before HX2 is diverted through EXP1 and the expander stream finally join the return flow after these two heat exchangers.

\section{CONCLUSIONS}

1 The best FOM is achieved at $5 \mathrm{~K}$ and $10 \mathrm{~K}$ approach temperature of regenerator and heat exchanger respectively. The highest value of FOM obtained is approximately .78 .

2. The relationships between the liquid production and the isentropic efficiency of expanders are almost linear .

3. Both yield and FOM increases with increase in expander inlet temperature. The liquid yield rise is more sensitive than the fom,

\section{REFERENCES}

[1] Barron R F “Cryogenic Systems"e, second edition, New York, Oxford University Press, 1985.

[2] S.Prasad "Study Cryogenics Cycles with ASPEN - HYSYS simulation" N.I.T Rourkela 2009.

[3] SciverS.W.V.“"Heliumcryogenics",Timmerhaus K.D.,RizzutoC."International cryogenics monograph series Pentium publishing corporationNew York, 1986.

[4] Ventura G,RisegariL."The art of cryogenics low-temperature experimental techniques" published in Elsevier Ltd, 2008.

[5] Kraft AA et al. Effect of composition and method of freezing on microbial flora of ground beef patties. J Food Sci 1979; 44:350-5.

[6] Chakrabarti R, Chaudhary DR. Advantages of liquid nitrogen freezing of penaeusmonodon over conventional plate freezing Fishery Techno 1987;24:44-7.

[7] Chattopadhyay P, Roy AK, Lala S. Studies on Transportation of wet fish IV. Use of liquid nitrogen as a secondary refrigerant. J Food SciTechnol 1987;24:178-80.

[8] Chen YL, Bonnie SP. Freezing tilapia by airblast and liquid nitrogen - freezing point and freezing ate. Int J Food Sci Technol1995;30:159-66.

[9] Goswami TK, Das H, Bose AN. A system design for transportation of frozen fish using liquid nitrogen. In: Proceedings of INCONCRYO'85. 1985, p. 332-41.

[10] Klein, S.A. 2012. Engineering Equation Solver.VersionV9.205 3-D. F Chart Software. 